\title{
A Study on the Solution and Gas-Phase Chemistry of Mn(III) and Fe(III) Tetraarylporphyrin Complexes by Fast-Atom Bombardment Mass Spectrometry. 1: Generation of Molecular Signals
}

\author{
Federico Maria Rubino \\ ITBA-CNR, Milano, Italy
}

\author{
Stefano Banfi, Gianluca Pozzi, and Silvio Quici \\ Centro CNR Sintesi e Stereochimica di Speciali Sistemi Organici, Milano, Italy
}

\begin{abstract}
Fast-atom bombardment mass spectrometry has been used to investigate the chemical behavior of $\mathrm{Fe}$ (III) and Mn(III) tetraarylporphyrins (TAP) in both the condensed and gas phases and to clarify the mechanisms responsible for the production of positive and negative ions. The differences in the behavior of $\mathrm{Fe}$ (III) and $\mathrm{Mn}$ (III) complexes in the positive ion mode could be correlated with those in their electronic structures and knowledge of the mechanism for the generation of negatively charged species was applied to characterize the counterion coordinated to the Mn(III)-TAP. Thus, the unprecedented, complete characterization of even complex Mn(III)-TAP was made pussible. (J Am Soc Mass Spectrom 1993, 4, 249-254)
\end{abstract}

$\mathrm{T}$ The functionalization of hydrocarbons through ac tivation of $\mathrm{C}-\mathrm{H}$ bonds is of great practical importance in organic chemistry [1] and is a subject for investigation from both a fundamental and a biochemical point of view (for an example of involvement in the mechanism of chemical carcinogenesis, see ref 2). Base models for this study include the gas-phase reaction of metal ions with hydrocarbons and other simple organic molecules, as recently reviewed [3].

Metallotetraarylporphyrins (M-TAP) have recently aroused increasing interest both as oxygenation catalysts [4] and as mechanistic probes for understanding the chemistry of cytochrome P-450 enzymes [5]. Factors affecting catalytic activity of $\mathrm{Mn}(\mathrm{III})-\mathrm{TAP}(X)$ in alkene epoxydation and alkane hydroxylation with $\mathrm{NaClO}$ or $\mathrm{H}_{2} \mathrm{O}_{2}$ as oxygen donors have been extensively investigated [6]. Among these, of particular importance are (1) the amount and nature of heterocyclic nitrogen bases as axial ligands either covalently linked to the porphyrin or free in the organic phase [6b, 7]; (2) the presence of lipophilic carboxylic acids as cocatalysts for the activation of $\mathrm{H}_{2} \mathrm{O}_{2}[8]$; and (3) the nature of the counterion $(\mathrm{X})(\mathrm{X}=\mathrm{Cl}, \mathrm{Br}, \mathrm{AcO}, \ldots)[9]$.

Address reprint requests to Federico Maria Rubino, ITBA-CNR, v. Ampere 56 I-20131, Milan, Italy.
The use of mass spectrometry for the structural characterization of porphyrin metal complexes has been widely exploited. In particular, modern techniques of desorption ionization [mainly desorption chemical ionization, laser desorption, and fast-atom bombardment (FAB)] have shown great advantages in this field for the analysis of thermally labile complexes [10-13] and for those of an ionic nature, such as M(III)-TAP (M = Fe, Mn, Ag) [14-16]. Naylor et al. [15] extensively investigated the processes undergone by $\mathrm{M}$ (II) and (III) porphyrins (M-P) under $F A B$ in a variety of matrices with relevance to acid-catalyzed demetallation and electron-transfer reactions. They concluded that M(III) complexes $(\mathrm{M}=\mathrm{Ag}, \mathrm{Mn})$ are relatively unaffected by the sputtering beam, mainly yielding the $\mathrm{M}-\mathrm{P}^{+}$species, whereas the $\mathrm{M}(\Pi)$ undergo several beam-induced reactions in solution. They further applied such knowledge to the determination of conformation and electrontransfer chemistry in superstructured porphyrins that mimic photosynthetic reaction centers [17].

Following our previous study on the mass spectrometric characterization of Mn(III)-TAP [16], we report here, and in our companion article [18], in greater detail on the solution and gas-phase chemistry undergone by some Fe(III)- and Mn(III)-TAP analyzed by FAB. Among the observed phenomena, we investi- 
gated (1) the occurrence of different ion types in the positive ion spectra of $\mathrm{Fe}$ (III) and $\mathrm{Mn}$ (III) complexes that could be correlated to the electronic structure of the metal center; (2) the generation of negatively charged species from which the nature of the anion coordinated to the complexed metal cation could be inferred; and (in our companion article [18]) (3) the formation of coordinative complexes in solution and in the gas phase with suitable molecules, such as $N$-alkylimidazoles and 4-t-butylpyridine; and (4) the conformation of "tailed" porphyrins carrying a number of side-chain functions, such as pyridine, imidazole, and carboxylate. Each of these aspects is important in highlighting the catalytic activity of $\mathrm{Mn}$ (III)- and Fe(III)-TAP as catalysts in hydrocarbon oxygenation reactions.

\section{Experimental}

The M(III)-TAP used in this study are shown in Table 1 . The synthesis of the unprecedented compounds will be reported elsewhere. The FAB matrices [3-nitrobenzyl alcohol (mNBA), 2-nitrophenyl-octyl ether (oNPOE), and thioglycerol] are commercially available

Table 1. Metallotetraarylporphyrins studied ${ }^{\text {a }}$
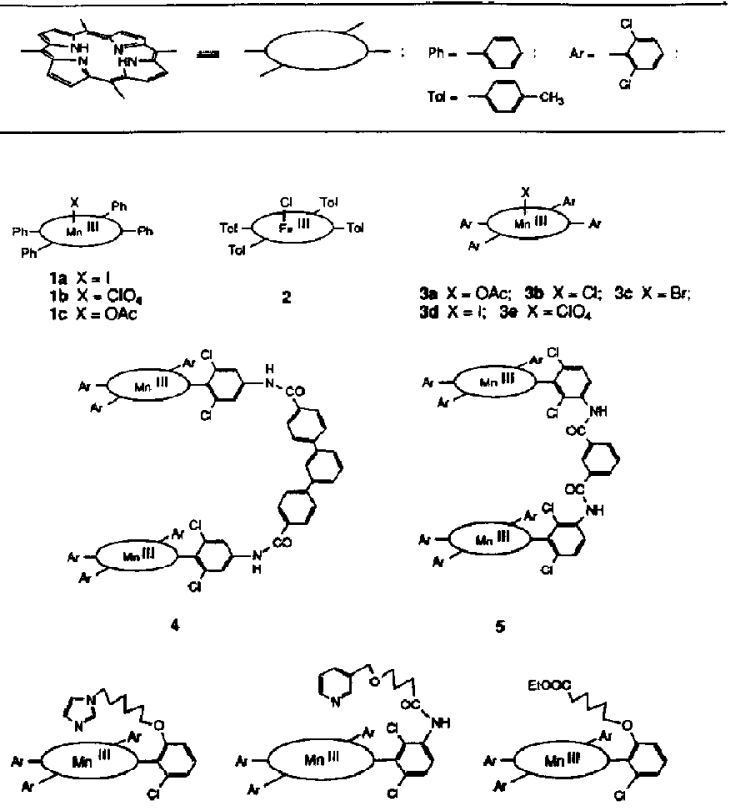

5

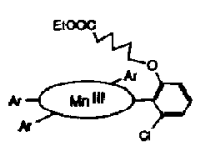

a
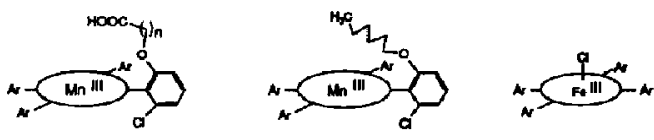

कीn=1; $\operatorname{sbn}-3 ; \operatorname{sen}=5$

${ }^{a}$ Ar, aryl group; Ph, phenyl: Tol, toluene

and were used as received. Porphyrin solutions at known concentrations were prepared in ethyl acetate and mixed with the matrix shortly before analysis.

Mass spectrometric measurements were performed on a Firuigan-MAT90 mass spectrometer with a standard $\mathrm{FAB}$ source and an IonTech atom gun (Xe, $5 \times$ $\left.10^{-5} \mathrm{mPa}, 8 \mathrm{keV}, 20 \mu \mathrm{A}\right)$ at better than unit resolution unless otherwise specified. The spectra of some compounds were also obtained in the laser desorption mode (no matrix added) on a LASERMAT (FinniganMAT, San Jose, CA) time-of-flight (TOF) mass spectrometer. A sample solution (1-2 $\mu \mathrm{L}$ ) in ethyl acetate was evaporated onto a gold-plated slide and desorbed by irradiation with pulses from an $\mathrm{N}_{2}$ laser operated at $322 \mathrm{~nm}$. In the case of polychlorinated compounds $\left(\mathrm{Cl}_{7}-\mathrm{Cl}_{16}\right)$, the indicated mass-to-charge ratio values are those of the most intense peak or of the centroid of the isotopic cluster, depending on instrumental resolution.

\section{Results and Discussion}

\section{Positive Ions}

The positive ion FAB mass spectra of the analyzed Mr(III) complexes 1 and 3-10 (Table 1) showed the Mn(III)-TAP ${ }^{+}$molecular signal, as expected from previous studies [16]. The spectra of Fe(III)-TTP(OAc) (2) featured only the Fe(III)-TTP ${ }^{+}$species when recorded from both mNBA and oNPOE. Forest et al. [14], while studying $\mathrm{Fe}(\mathrm{III})$-TPP(X) complexes $(\mathrm{X}=\mathrm{F}, \mathrm{Cl}, \mathrm{Br}, \mathrm{I})$, observed $F A B$ signals due to the molecular peak $\mathrm{Fe}$ (III)-TPP $(\mathrm{X})^{+}$and to the Fe(III)-TPP ${ }^{+}$fragment, the ratio of the two increasing in the order $\mathrm{I}<\mathrm{Br}<\mathrm{Cl}<\mathrm{F}$. The strength of the bond between the metal and the counterion obviously determines the abundance of the molecular signal, which appears to be independent of the matrix used because spectra recorded from all three matrices yielded essentially the same results.

The differences in the mass spectral behavior between $\mathrm{Mn}$ (III) and $\mathrm{Fe}$ (III) high-spin complexes may be explained on the basis of their different electronic structures [19]. In the Mn(III) complexes, the four lowest $d$ orbitals are singly occupied, and the strongly antibonding $b 1 g\left(d_{x 2-y_{2}}\right)$ remains empty, whereas in the Fe(III) complexes it is singly occupied. As previously reported, $\mathrm{Mn}$ (III)-TAP(X) complexes yield only the $\mathrm{Mn}(\mathrm{III})-\mathrm{TAP}^{+}$species, thus behaving as ion pairs, and this is also due to the lower strength of the coordinative bonds between the metal and the axial ligand (Scheme I).

$\mathrm{Fe}(\mathrm{III})-\mathrm{TAP}(\mathrm{X})$ complexes are on the contrary desorbed as positive molecular species through the loss of the antibonding electron on the metal center. This species can be envisaged either with an Fe(IV) metal center [the (TAP $\left.\mathrm{Fe}^{\mathrm{IV}}-\mathrm{O}\right)^{+}$oxene is currently postulated as the oxidizing species in the catalytic cycle of cytochrome P-450 and of its biomimetic models [20]] or as an Fe(III) complex of the porphyrin cation radical 


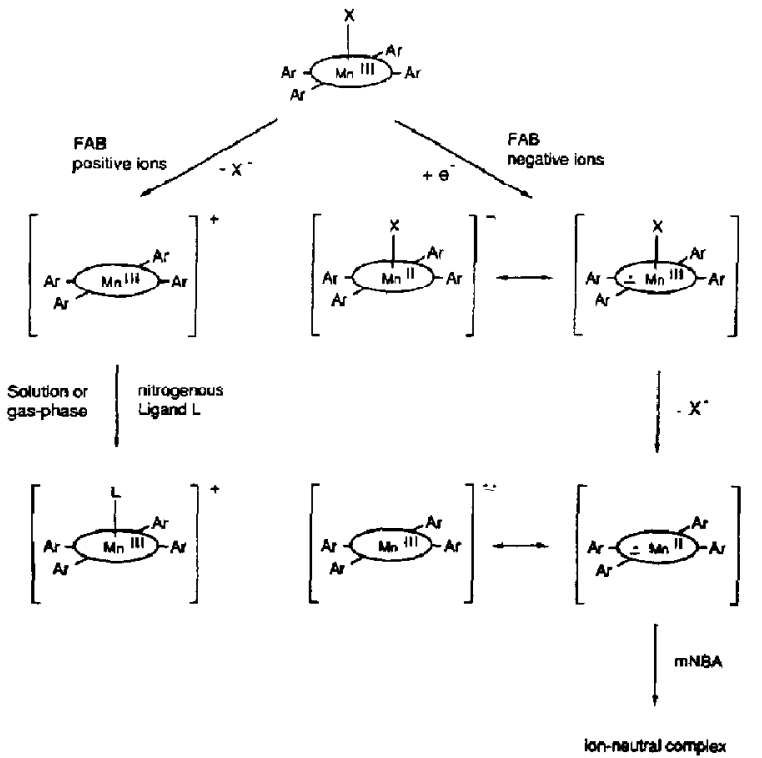

Scheme I

[21]. Subsequent loss of the anionic ligand as a radical species leaves the system in the Fe(III) state capable of undergoing axial complexation by a heterocyclic nitrogen base (Scheme II), as is demonstrated in our companion article [18].

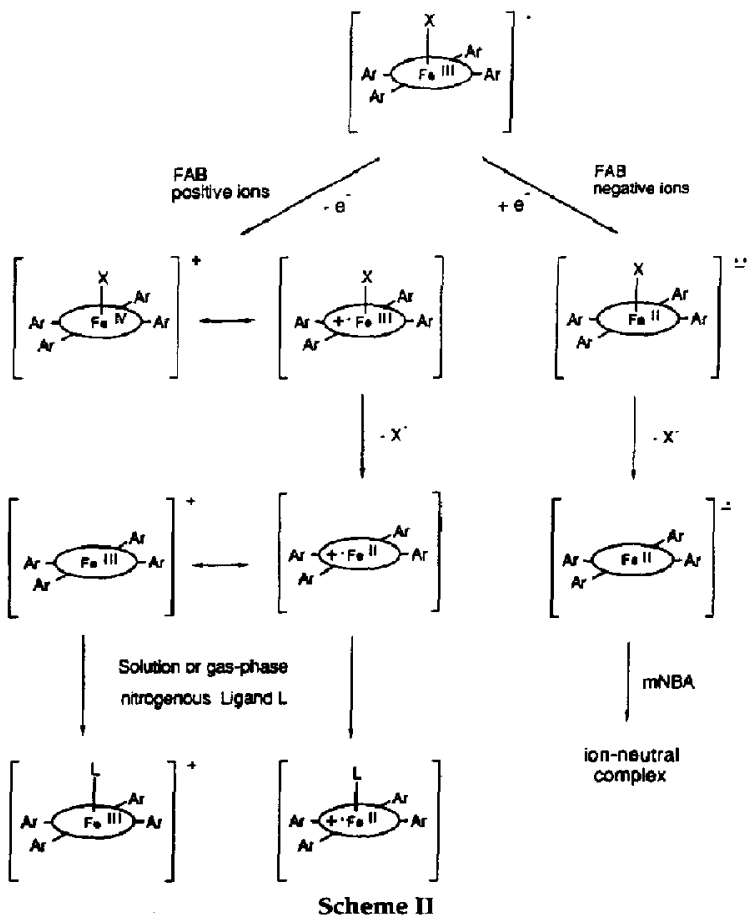

\section{Negative Ions}

Negative ion spectra of some M-TAP obtained by chemical ionization [22], desorption chemical ionization $[13,23]$, and laser desorption/Fourier transform mass spectrometry [24], but not by $F \wedge B$, has been reported. Mn(III)- and Fe(III)-TAP undergo thermal electron capture and yield several ion-neutral molecule complexes that on the contrary, had negligible if any abundance in the positive ion spectra (Figure 1).

When mNBA is the matrix, the most intense signals in the spectra of $\mathrm{Mn}$ (III)-TPP(X) [X - I(1a) and $\mathrm{ClO}_{4}$ (1b)] are those generated by electron capture from the complex ( $m / z 794$ and 766 , respectively): that in which mNBA is the ligand ( $m / z 820)$ and that corresponding to the unligated species $(m / z 667)$, as shown in Figure 1 (top and middle panels). The observed signal at $m / z$ 713 is probably due to an ion-neutral inolecule coinplex between $\mathrm{Mm}$ (III)-TPP and $\mathrm{NO}_{2}$ [25] released from mNBA under particle bombardment. Fe(III)-TTP(C1)(2) yields the molecular anion $(m / z 759 / 761)$, the coordinated species with mNBA ( $m / z 877$ ), and the unligated species $(m / z$ 724) (Figure 1 , bottom panel). Surprisingly, Mn(III)-TPP(OAC) (1c) does not yield the expected molecular signal at $m / z 726$ but only those at $m / z 667,713$, and 820 .

The most striking difference between the positive and negative ion spectra of both $\mathrm{Mn}$ (III) and Fe(III)
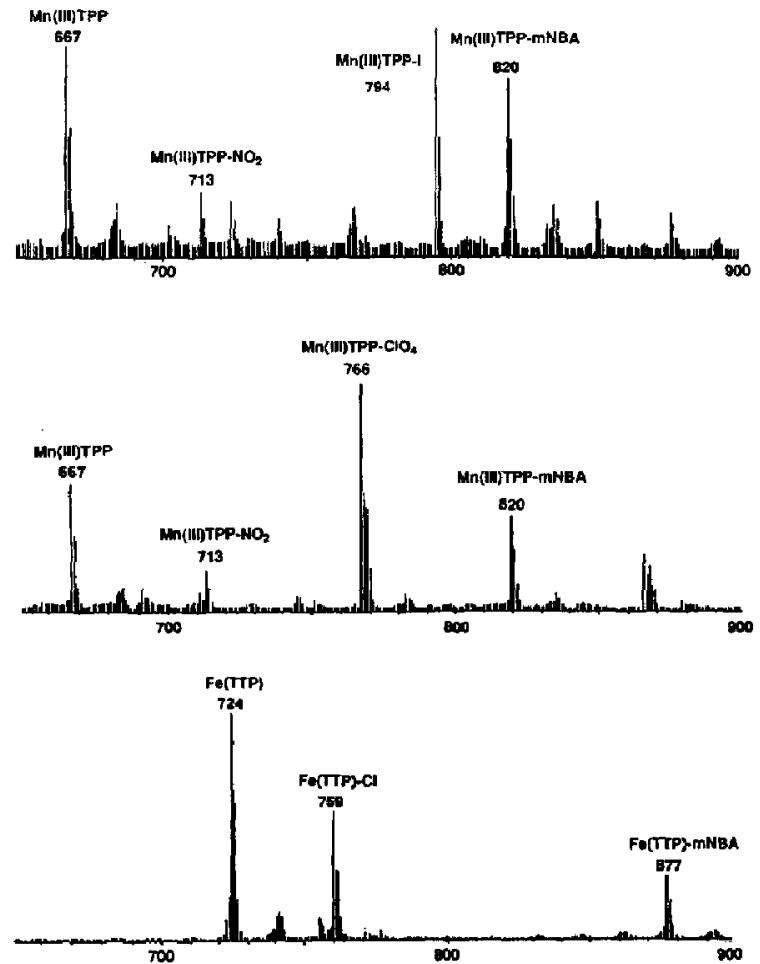

Figure 1. Negative ion FAB mass spectra of $\mathrm{Mn}$ (III)-TPP(I), Mn(III)-TPP(ClO $)_{4}$, and Fe(III)-TTP(Cl). Matrix is mNBA. 
complexes recorded from an $\mathrm{mNBA}$ matrix is that in the negative ion mode, sensitivity is far lower than that expected from the operating ionization mechanism. Indeed, whereas in the positive ion mode, even the traces of one compound remaining on the target may be seen in the next spectrum, the negative ion spectra are insensitive to contamination. This observation is at first surprising because thermal electron capture is known as the most sensitive method for ion generation from compounds with low-lying unoccupied orbitals, but it may be explained on the basis of recent work on the negative ion $\mathrm{FAB}$ behavior of some deoxyribonucleotides and analog compounds [26]. The authors correlate the $\mathrm{M}^{-}$. versus $[\mathrm{M}-\mathrm{H}]^{-}$ratio in the spectra of the same compound recorded from different matrices with the energy of the lowest unoccupied molecular orbital for each matrix, thus assuming that matrix and sample molecules compete for capture of thermalized electrons produced under particle bombardment. Both mNBA and oNPOE are strongly electron-capturing molecules; therefore it is conceivable that only relatively concentrated solutions of M(III)TAP complexes can yield an observable signal. Changing the matrix from $\mathrm{mNBA}$ to thioglycerol (a far less effective electron-capturing compound), increases the intensity of the molecular signal at least twentyfold, and the ratio between the $\mathrm{Mn}$ (III)-TAP ${ }^{-}$and $\mathrm{Mn}$ (III)$\mathrm{TAP}(\mathrm{Cl})^{--}$signals is also different, as shown in Figure 2 for compound $\mathbf{3 b}$.
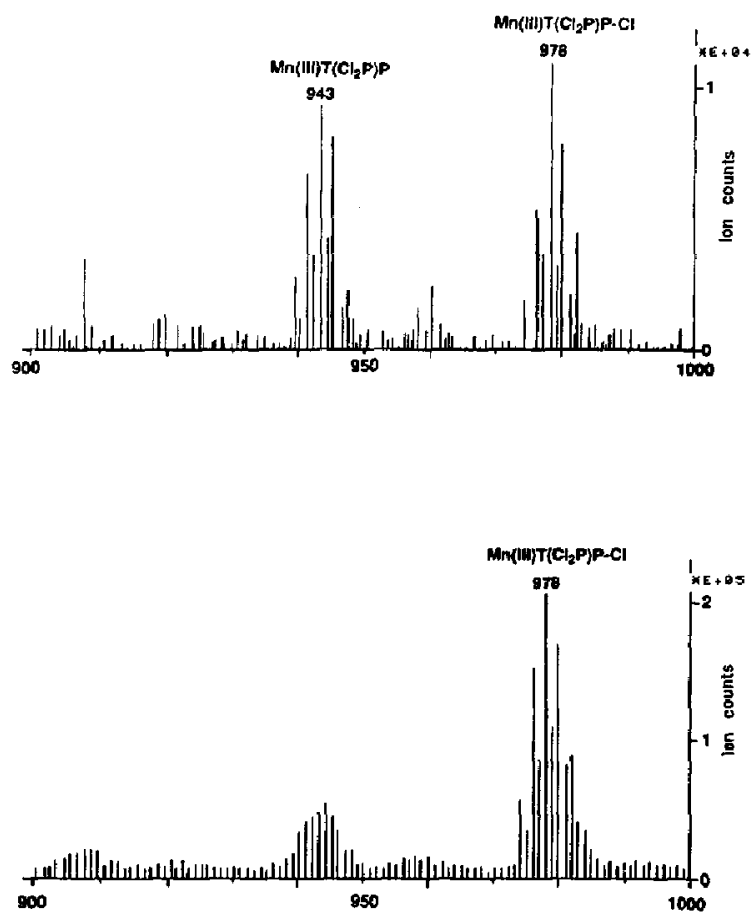

Figure 2. Negative ion $\mathrm{FAB}$ spectra of $\mathrm{Mn}(\mathrm{III})-\mathrm{T}\left(\mathrm{Cl}_{2} \mathrm{P}\right) \mathrm{P}(\mathrm{Cl})$. Matrix is (top) $\mathrm{mNBA}$ and (bottom) thioglycerol.
Thermal electron capture under FAB is also independent of the electron-withdrawing character of the substituents on the aryl rings, as demonstrated by the similar peak ratios obtained for Mn(III)-TPP (1) and for its analog $\mathrm{Mn}(\mathrm{III})-\mathrm{T}\left(\mathrm{Cl}_{2} \mathrm{P}\right) \mathrm{P}(3)$ (compare the spectra in Figure 1 with those in Figure 5); therefore the captured electron appears to be hosted by the annulene-metal system. Because the lowest lying antibonding orbitals have a prominent metal character, it is also conceivable that the thus-formed species may be formulated as the elusive M(II)-TAP complexes [4b, 27].

The FAB chemistry discussed above also allows us to explain the positive ion spectra obtained from novel dimeric Mn(III)-porphyrins 4 and 5. The spectrum of compound $\mathbf{5}$ is reported as an example in Figure 3. Electron capture from one of the two covalently linked Mn(III)-porphyrins generates the signal at $m / z 2049$, whereas desorption of the doubly charged species $(\mathrm{m} / \mathrm{z}$ 1025) is due to competition of the matrix (mNBA) for thermalized free electrons in solutions. The signals at $m / z 1060,956$, and 985 are fragments due to a single porphyrin ring through fission around the amido linkages. The spectrum of compound $4\left(\mathrm{M}^{+} 2198\right)$ shows very similar fragmentation.

The same pattern may also justify the data reported by Meunier and co-workers [28] for the Fe(III) and Mn(III) complexes of "mixed ellipticinium-porphyrin," which carry two positive charges. FAB mass spectrometric analysis, as reported, shows only the singly charged product due to one-electron reduction, either of the porphyrin moiety or of the ellipticinium system (reduction of quaternized pyridinium salts under FAB is a well-recognized process [29]) and reveals neither the peak due to a doubly charged ion nor that due to coupling of one of the two charged moieties with a counterion.

The overall picture obtained from the positive and negative ion $F A B$ spectra is also confirmed from the laser desorption spectra recorded without matrix addition on a recently available TOF instrument. The spectra of $\mathrm{Mn}(\mathrm{III})-\mathrm{T}\left(\mathrm{Cl}_{2} \mathrm{P}\right) \mathrm{P}$ with different counterions $\left(\mathrm{AcO}, \mathrm{Cl}, \mathrm{Br}, \mathrm{I}, \mathrm{ClO}_{4}\right)(3 \mathrm{a}-3)$ obtained in the positive ion mode feature only the cluster at $m / z$ 943, whereas the negative ion mode spectra show a prominent low-

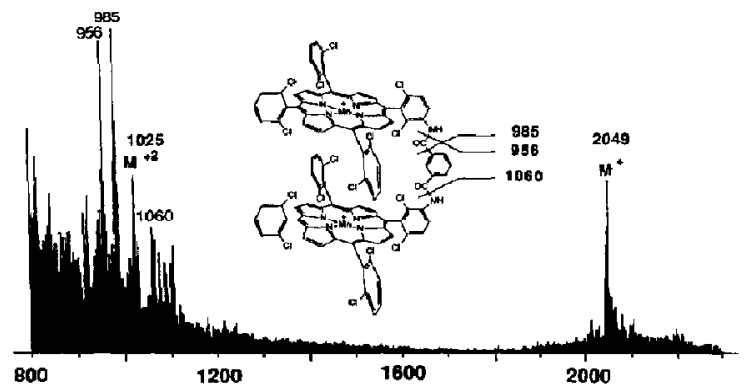

Figure 3. Positive ion FAB spectrum of dimeric Mn(III)-TAP (5) Matrix is mNBA. 
mass peak due to the anion and a very weak one corresponding to the negatively charged ion pair, as exemplified by that at $m / z$ 978 shown in Figure 4 for compound $3 \mathbf{b}$. The low abundance of the signal due to electron capture in the negative ion TOF spectra is of course explained by lack of a suitable environment for bimolecular electron-transfer reactions in the dry sample subject to laser desorption, whereas, on the contrary, such reactions are possible in the solution of the sample subject to FAB analysis. This observation indeed supports the conclusion that electron capture only occurs in solution and not in the gas phase.

The finding that thioglycerol is a better matrix compared with mNBA for the production of negatively charged M(III)-TAP species under FAB is of value in demonstrating the nature of the porphyrin counterion, which is very important in terms of catalytic activity. Indeed, the catalytic efficiency of $\mathrm{Mn}(\mathrm{III})-\mathrm{T}\left(\mathrm{Cl}_{2} \mathrm{P}\right) \mathrm{P}(3)$ in biomimetic oxidation in the presence of heterocyclic nitrogen ligands has been recently demonstrated to be affected by the nature of the coordinated counterion. Strongly coordinating anions such as chloride hamper the formation of the complex with the lipophilic nitrogen ligand, which is an essential species in the catalytic cycle $[9,30]$. Although in some cases the shift of the Soret band in the electronic absorption spectra may be informative, UV-visible spectrophotometry is not particularly useful if a mixture of coordinating anions or neutral molecules, or both, is suspected to be present.

Recombination of radicals in solution [31] may also explain the presence, in the negative ion $\mathrm{FAB}$ spectra of $\mathrm{Mn}(\mathrm{III})-\mathrm{T}\left(\mathrm{Cl}_{2} \mathrm{P}\right) \mathrm{P}$ with different counterions, of a very strong signal due to a chlorine adduct (Figure 5), even if both spectrophotometric analysis and laser desorption TOF mass spectrometry data ruled out the presence of any chloride impurity. Reductive radical dechlorination of polychlorinated porphyrins has been previously demonstrated in the positive ion spectra [16], and it is analogous to other similar processes

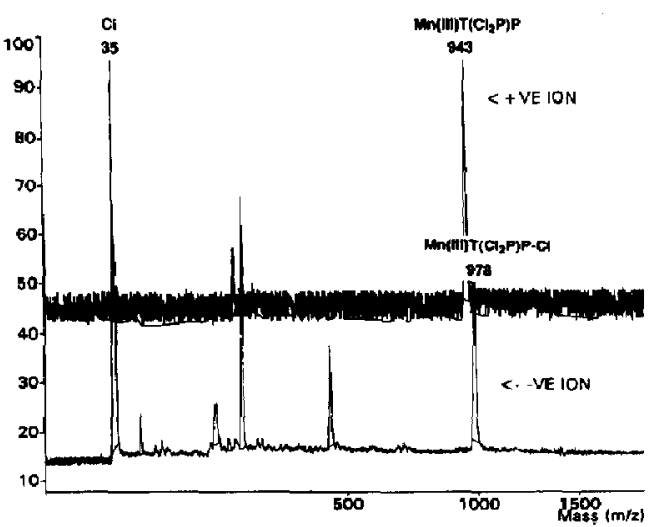

Figure 4. Laser desorption TOF spectra (positive and negative ions) of $\mathrm{Mn}(\mathrm{III})-\mathrm{T}\left(\mathrm{CL}_{2} \mathrm{P}\right) \mathrm{P}(\mathrm{Cl})$
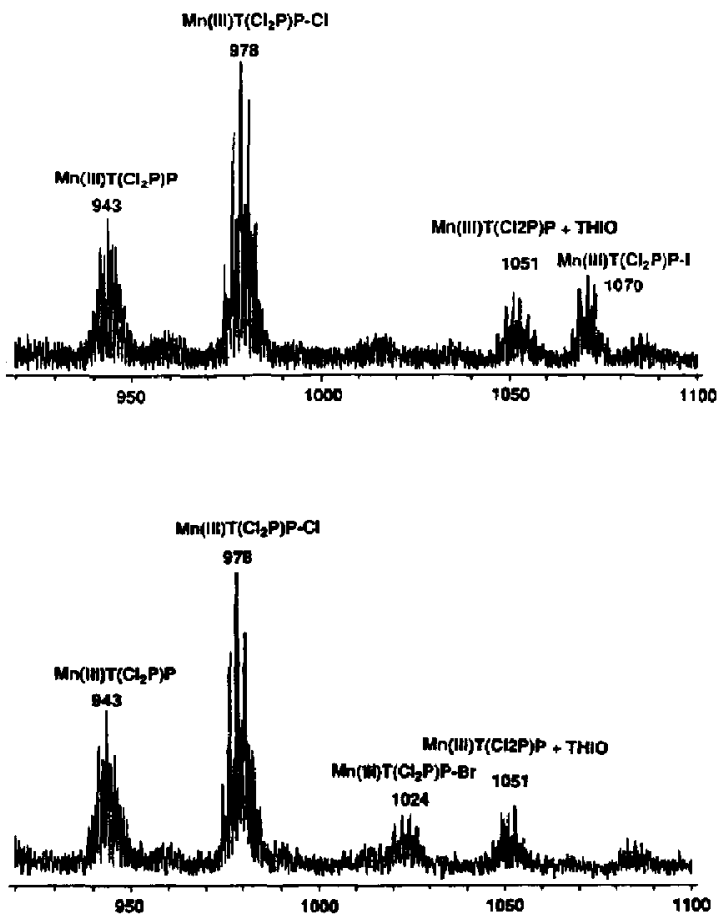

Figure 5. Negative ion spectra of $\mathrm{Mn}(\mathrm{III})-\mathrm{T}\left(\mathrm{Cl}_{2} \mathrm{P}\right) \mathrm{P}(\mathrm{I})$ (3d) and $\mathrm{Mn}(\mathrm{III})-\mathrm{T}\left(\mathrm{Cl}_{2} \mathrm{P}\right) \mathrm{P}\left(\mathrm{ClO}_{4}\right.$ ) (3e) (matrix is thioglycerol (THIO)).

observed in several organic compounds [31, 32]. The negative ion $\mathrm{FAB}$ spectra of both Mr(III)- and Fe(III)TAP(OAc) sometimes also show a minor peak $15 \mu$ higher than the free metal porphyrin, corresponding to formal $\mathrm{CO}_{2}$ elimination from the acetate ligand (i.e., to ligation by a methyl species). We believe that the acetate radical undergoes a Kolbe-like decarboxylation to yield a methyl radical, which then combines with the porphyrin radical anion to yield a methyl complex analogous to similar species (methylcobalamine) known for vitamin $B_{12}$ [33].

\section{Conclusions}

The results reported here allow rationalization of the several reaction pathways of M(III)-TAP under FAB conditions, thus making mass spectrometry an attractive tool for the structural analysis of even complex porphyrin molecules. In particular, selection of the correct matrix for either ion polarity allows the observation of important ions that would otherwise go undetected and the complete characterization of the counterion, particularly in the case of the Mn(III) complexes. Moreover, the overall pattern of mass spectrometric reactivity depicted in Schemes I and II can be applied to the synthesis and characterization of supramolecular species, such as those with axial ligands, as is reported in our companion article [18]. 


\section{Acknowledgment}

We are grateful to Drs. L. Simonotti (Finnigan MAT, Italy) and M. Stevenson (Finnigan MAT, UK) for recording the spectra on the new LASERMAT instrument.

\section{References}

1. Simà, L. I., Ed. Dioxygen Activation and Homogeneous Catalytic Oxidation; Elsevier; Amsterdam, 1991.

2. Hanzlich, R. P.; Ling, K.-H. J. J. Org. Chtem. 1990, 55 , 3992-3997.

3. Eller, K.; Schwartz, H. Chem. Rev. 1991, 91, 1121-1177.

4. Meunier, B. Bull. Chem. Soc. Ipn. 1986, 578-594; (b) Tabushi, I. Coord. Chem. Rev. 1988, 86, 1-42; (c) Gunter, M. J.; Turner, P. Coord. Chem. Rev. 1961, 708, 115-161.

5. Ortiz de Montellano, P. R. Cytochrome P-450, Structure, Mechantism and Biachemistry; 1986. Plenum Press: New York.

6. (a) Montanari, F.; Banfi, S.; Pozzi, L.; Quici, S. Rev. Heterocycl. Chem. 1992, 6, 94-141; (b) Banfi, S.; Montanari, F.; Quici, S. Rec. Trav. Chim. Pays-Bas 1990, 109, 117-122; (c) Banfi, S.; Maiocchi, A.; Montanari, F.; Quici, S. Gazz, Chim. Ital, 1990, $120,123-130$

7. Banfi, S.; Legramandi, F.; Montanari, F.; Pozzi, G.; Quici, S. J. Chem. Soc. Chem. Conmun. 1991, 1285-1287.

8. (a) Anelli, P. L.; Banfi, S.; Montanari, F.; Quici, S. J. Chem. Soc. Chum. Cummun. 1989, 779-780; (b) Banfi, S.; Maiouchi, A.; Moggi, A.; Montanari, F.; Quici, S. I. Chem. Soc. Chem. Commun. 1990, 1794-1796.

9. Banfi, S.: Montanari, F,; Quici, S.; Torossian, G. I. Inclusion Phenomena Mol. Recognition Chem. 1992, 12, 159-173.

10. Kurlansik, L.; Williams, T. J.; Campana, J. E.; Green, B. N.; Anderson, L. W.; Strong, J. M. Biochem. Biophys. Res. Commun. 1983, 111, 478-483.

11. Kurlansik, L.; Williams, T. J.; Strong, J. M.; Anderson, L. W.; Campana, J. E. Biomed. Environ. Mass Spectrom. 1984, 11, 175-481.

12. Zhang, M. Y.; Liang, X.-Y.; Chen, Y.-Y.; Liang, X.-G. Anal. Chem. 1984, 56, 2288-2290.

13. Forest, E.; Marchon, J. C.; Ulrich, J.; Virelizier, H. Inorg. Chenn. 1986, 25, 3570-3572.

14. Forest, E.; Marchon, J. C.; Wilkins, C. L.; Yang, L.-C. Org. Mass Spectrom. 1989, 24, 197-200.
15. Naylor, S.; Hunter, A.; Cowen, J. A.; Lamb, J. H.; Sanders, J. K. M. J. Am. Chem. Soc. 1990, 112, 6507-6514.

16. Rubino, F. M.; Mascaro, P.; Banfi, S.; Quici, S. Org. Mass Spectrom. 1991, 26, 161-166.

17. Naylor, S.; Cowan, J. A.; Lamb, J. H.; Hunter, C. A.; Sanders, J. K. M. J. Chem. Soc. Perkin Trans. 2, 1992, 411-418.

18. Rubino, F. M.; Banfi, S.; Pozzi, G.; Quici, S. J. Am. Soc. Mass Spectrom., 1993, 4, 255-258.

19. (a) Zerner, M.; Goutermann, M. Theor. Chim. Acta 1966, 4 44-63; (b) Zerner, M.; Goutermann, M.; Kobayashi, II. Theor. Chim. Acta, 1966, 6, 363-400; (c) Boucher, L. J. Coord. Chem. Rev. 1972, 7, 289-329; (d) Scheidt, W. R.; Reed, C. A. Chem. Rev. 1981, 81, 543-555; (e) Gunter, M. J.; Turner, P. J. Mol. Catalysis 1991, 66, 121-141.

20. (a) Groves, J. T.; Watanabe, Y. J. Am. Chem. Soc. 1986, 108, 507-508; (b) Tsychiya, S. J. Chem. Soc. Chem. Commun. 1991, $716-717$.

21. (a) Bruice, T. C.; Zipplies, M. F.; Lee, W. A. Proc. Natl. Acad. Sci. USA 1986, 83, 4646-4649; (b) Adams, P. A.; Gold, R. D. I. Chem. Soc. Chem. Commun. 1990, 97-98.

22. Dillow, G. W.; Gregor, I. K. Org. Mass Spectrom. 1988, 23 , 777-782.

23. Forest, E.; Ulrich, J.; Marchon, J. C.; Virelizier, H. Org. Mass Spectrom. 1987, 22, 45-48.

24. Brown, R. S.; Wilkins, C. L. Anal. Chem. 1986, 58, 3196-3199.

25. Chen, H. L.; Hagan, T. E.; Groh, S. E; Ridge, D. P. I. Am. Chem. Soc. 1991, 113, 9669-9670.

26. Laramee, J. E.; Arbogast, B.; Deinzer, M. L. Anal. Chem 1989, 61, 2154-2160.

27. Tabushi, T.; Knga, N. I. Am. Chem. Soc. 1979, 101, 6456-6458.

28. Moghadam, G. E.; Ding, L.; Tadj, F.; Meunier, B. Tetrahedron 1989, 45, 2641-2648.

29. Ryan, T. M.; Day, R. J.; Cooks, R. G. Anal, Chem. 1980, 52, 2054-2057.

30. Banfi, S.; Montanari, F.; Quici, S. J. Org. Chem 1989, 54, $1850-1859$

31. Detter, L. D.; Hand, O. W.; Cooks, R. G.; Walton, R. $\Lambda$. Mass Spectrom. Rev. 1988, 7, 465-502.

32. De Angelis, F.; Doddi, G.; Ercolani, G. J. Chem. Soc. Perkin Trans. 2, 1987, 633 .

33. (a) Lexa, D.; Saveant, J. M. I. Am. Chem. Soc. 1978, 100, 3220-3221; (b) Scheffold, R.; Dike, M.; Dike, S; Herold, T.; Walder, L. I. Am. Chem. Soc. 1980, 102, 3642-3644. 